\title{
Fuzzy Logic-based Dual Axis Solar Tracking System
}

\author{
Dola Sinha \\ Department of Electrical Engg, \\ Dr. B. C. Roy Engineering College, \\ Durgapur, India
}

\author{
Nirmal Baran Hui \\ Department of Mechanical Engineering, \\ NIT, Durgapur, India
}

\begin{abstract}
Increment of efficiency of solar power system using Dual Axis Sun Tracker (DAST) through PID controller and Light Detecting Resistors (LDR) has been attempted in this paper. The model is simulated in the MATLAB/SIMULINK environment initially. Later in a hardware model is fabricated with the help of four sensors placed in the four sides of the panel to sense the position of the sun and two DC series motors to rotate the solar panel. To improve this hardware system, computer interfacing is made so that the solar panel can move smoothly in both the direction i.e., East to West and North to South. PID controller is designed in MATLAB/SIMULINK. To enhance its efficiency the gains of the PID controller are tuned using the Fuzzy logic controller. This simulation model is interfaced with the hardware model through an Audrino Mega board. The results are approaching the feasible limit for real implementation and can be applied for large solar power system.
\end{abstract}

\section{Keywords}

Solar tracking system, DAST, PID controller, Fuzzy logic controller, LDR

\section{INTRODUCTION}

Demand of electricity is steadily increasing day-by-day. The classical high power station cannot fulfill the load demand in near future. Also, it increases, the environment pollution leading to global warming. Therefore, researchers are looking towards renewable and clean energy resources. Solar energy is one of such promising clean and renewable energy resource [1-3]. A number of photovoltaic (PV) cells interconnected each other constitute a PV panel and converts solar energy to DC electricity [1-3]. In order to get maximum efficiency, Solar panel needs to be placed perpendicular to the Sun and demand for a solar tracking system. It has been observed that a mobile PV panel driven through Sun tracker generates more energy compared to a fixed PV/Solar panel [4]. Two schemes are usually followed for solar tracking: single axis scheme [58] from east to west movement of the tracker and dual axis scheme [9-17] for both the east to west and north to south movement of the tracker. Dual axis scheme is found to be more efficient than the single axis one. However, dual axis scheme generally uses two motors (DC $[9,10,14,15]$ Stepper $[12,13])$ placed in perpendicular direction for a generation of two degrees of freedom leading to complex tracking strategies and demand for proper controller [18-20]. Fig. 1 shows the sun travelling path during different seasons. Fig. 2 shows the dual axis solar tracker.

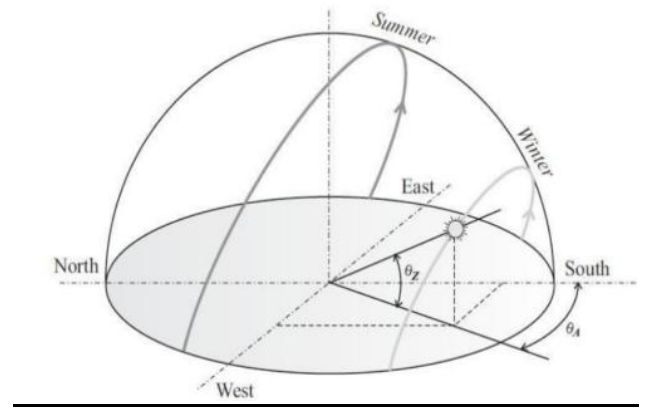

Fig.1 Typical behavior of the Sun travelling path.

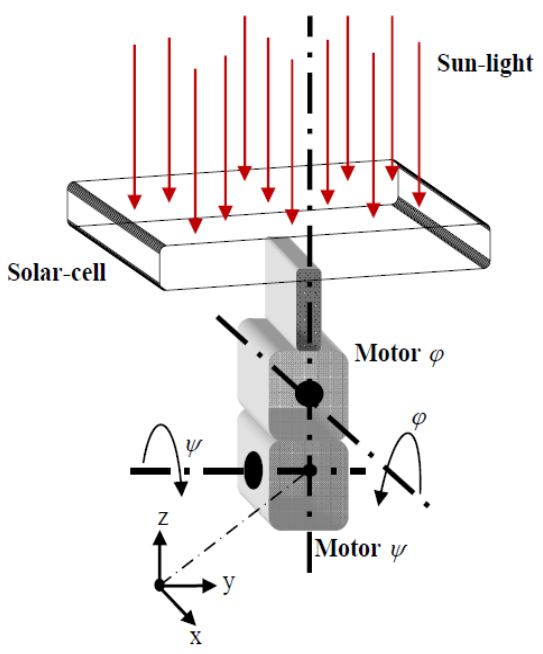

Fig.2: DAST based Solar Tracker

Solar tracking is the most appropriate technology to enhance the electricity production of a PV system. To achieve a high degree of tracking accuracy, several approaches have been widely investigated. Generally, they can be classified as either open-loop or closed loop tracking [18]. In the open-loop tracking, an analytical formula or control algorithm is used. Referring to the literature [19-23], the azimuth and the elevation angles of the Sun were determined by solar movement models or algorithms at the given date, time and geographical information. The control algorithms were executed in a microprocessor [24,25]. In the closed-loop tracking approach, various active sensor devices, such as charge couple devices (CCDs) [26-28] or light dependent resistors (LDRs) [25, 29-32] were utilized to sense the Sun's position. A feedback error signal was then generated by the control system to continuously receive the maximum solar radiation on the PV panel. The present paper proposes an empirical model in this matter. The rest of the paper is structured as follows: Section 2 of this paper describes the modeling of solar power system mainly in tracking system, DC-DC boost converter and DC-AC inverter. Results and discussions have been made in section 3. Finally, some 
conclusions have been drawn and future scopes are indicated in section 4 .

\section{DEVELOPMENT OF A SOLAR TRACKING SYSTEM}

To enhance the efficiency of the solar panel it is required to design the whole solar power system. In this paper automatically sun tracking control is achieved by PID controller. A dual axis sun tracker (DAST) has two degrees of freedom that act as axes of rotation (refer to Fig. 2). A DAST has been fabricated in our laboratory as shown in Fig. 3. The first axis is a vertically pivoted shaft that allows the device to move to a compass point. The second one is a horizontal elevation pivot implanted upon the platform. The Azimuth motor rotates along the vertical axis to adjust azimuth position of the Sun. A second motor will operate the panel elevation acting on the horizontal axis to altercate the sun altitude. Using a combination of the two axes, any location in the upward hemisphere could be pointed. Four LDR (light detecting resistor) sensors are used in the four sides of the panel, which can sense the position of the sun. LDR can detect the voltage across them. If any voltage difference occurs in LDR on the two opposite sides, the panel can move and make a voltage difference zero. This means the light can equally distribute to the whole panel. Two sensors are responsible for east to west direction that is for the whole day and the other two sensors are used for north to south movement that is for the whole year. Two DC series motors are used to rotate the solar panel and the speed of the motor is controlled by PID controller. A fuzzy logic based controller is also used to tune the gains of PID controller. The control circuit is presented in Fig. 4.

\section{CONTROLLER DESIGN}

Initially a simulation model was constructed using Matlab / Simulink as shown in Fig. 5. In order to stabilize and control the said system, the classical PID control strategy has been applied. Performance of PID control law largely depends on its gain values, Ziegler Nichols method-II has been applied to get controller gain values.

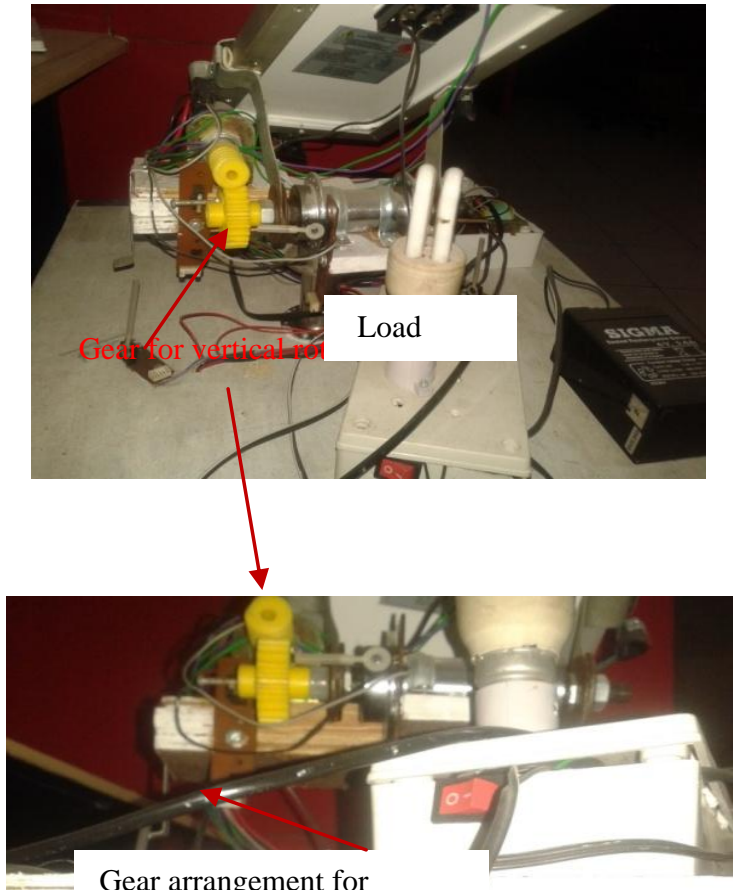

Gear arrangement for
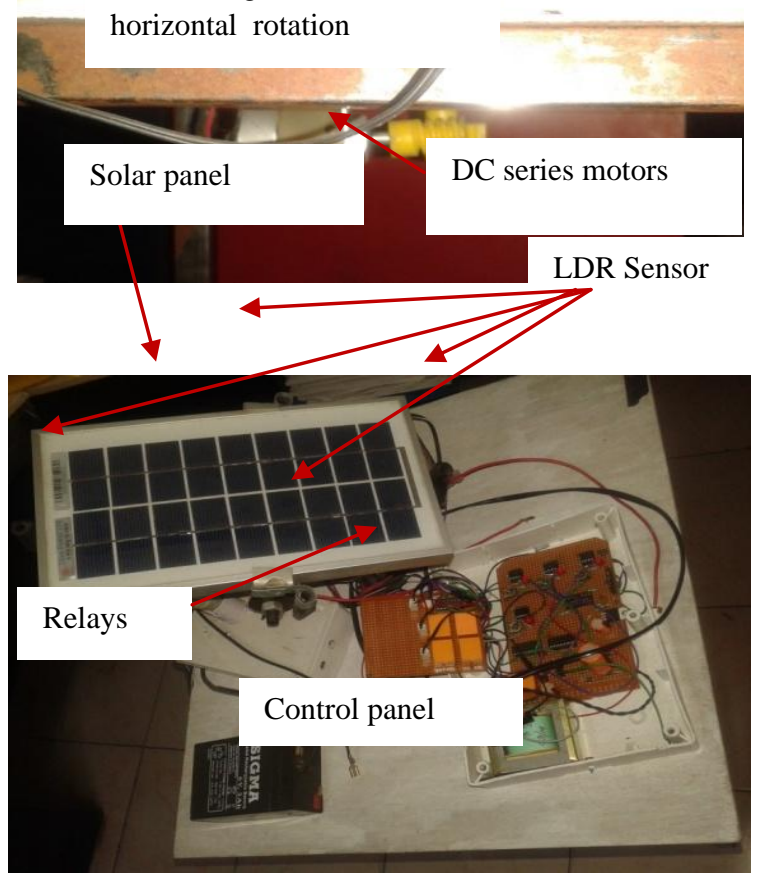

Fig. 3: A prototype model of the DAST-based solar system.

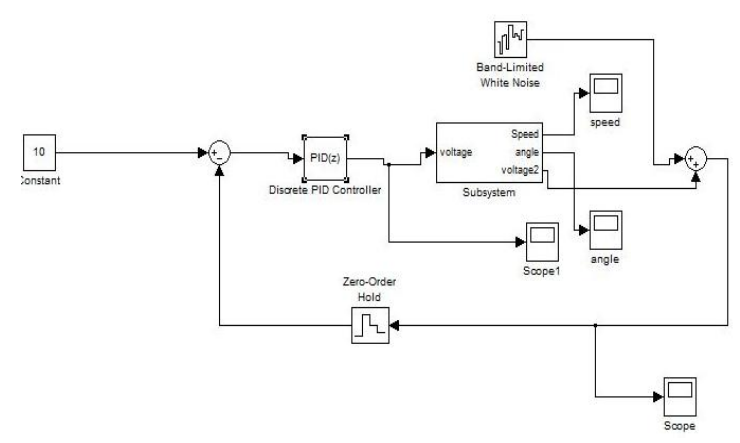

Fig. 4: Control circuit of the fabricated DAST. 


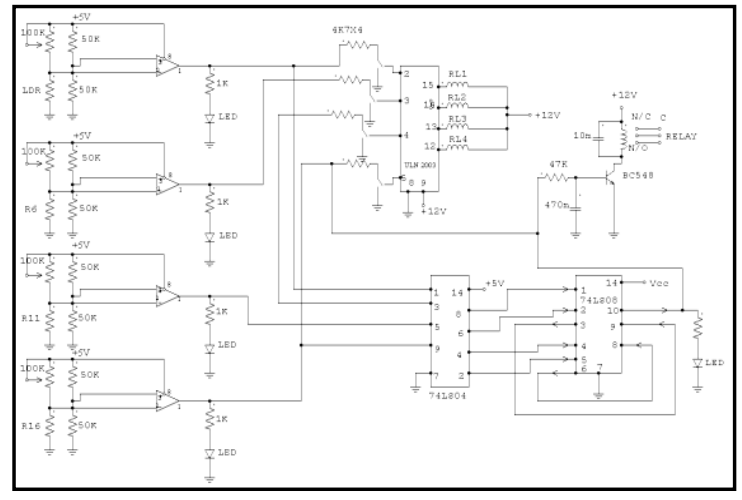

Fig. 5: Simulink model of the PID-controlled DAST system.

\subsection{Fuzzy Logic-Based Tuning Of Pid Controller}

Tuning of PID controller gains using Ziegler-Nichols method does not provide satisfactory results. It may be due to following reasons: (a) Constant gain values throughout the simulation time do not provide good result due to the nonlinearity present in the model; (b) It lacks robustness and adaptability.

Keeping in view of the above listed drawbacks of a PID controller, whose gains have been tuned using Ziegler-Nichols method, an attempt has been made to tune the controller gains using a Fuzzy Logic Controller (FLC). The FLC works on fuzzy set theory proposed by Zadeh. There are two major approaches of developing FLC: (i) Mamdani approach (ii) Takagi-Sugeno approach. In the present study, the PID controller was tuned using an FLC following Mamdani approach and simulation was carried out in MATLAB. The two condition variables used are: error $(\varepsilon)$ in pendulum angle (difference between the desired angular position of the pendulum and the present position) and differential change in error (derivative of error, $\dot{\varepsilon}$ ). The output consists of three gain values $K_{P}, K_{D}$ and $K_{I}$. The shape of membership functions is assumed to be triangular for simplicity. Fig. 6 shows the author-defined membership function distribution of both input as well as output variables. Three linguistic terms Low (L), Medium (M) and High $(\mathrm{H})$ have been considered for all the outputs and three linguistic terms have also been considered for outputs such as Negative Low (NL), Zero (Z) and Positive Low (PL). With three choices each for error and $d \_$error, there could be nine input combinations. For each of these nine input combinations, there could be three gain values, one each for $K_{P}, K_{D}$ and $K_{I}$. Thus, there could be at least nine rules in the rule base. These rules are set manually based on intuition and presented in Table 1 . One such rule could be as follows:

IF error is NL and d_error is $\mathbf{Z}$, THEN $K_{P}$ is $\mathbf{L}, K_{I}$ is $\mathbf{L}$ and $K_{D}$ is $\mathbf{H}$.

\section{RESULTS AND DISCUSSIONS}

A real prototype model is tested in this work, a photograph of which is shown in Figure 3. DC series motors are used for movement of solar panel and the speed of the motor is controlled by the armature voltage control method. And the armature voltage control can be achieved using PID controller. PID controller was tested with the following controller gains which are arbitrarily chosen: $\mathrm{Kp}=10, \mathrm{Kd}=4$ and $\mathrm{Ki}=2$. Responses of the system and speed-time graph is presented in Figures 8 and 9, respectively. It has been observed that the speed is fluctuating with time and it is never stabilized with arbitrary gains.
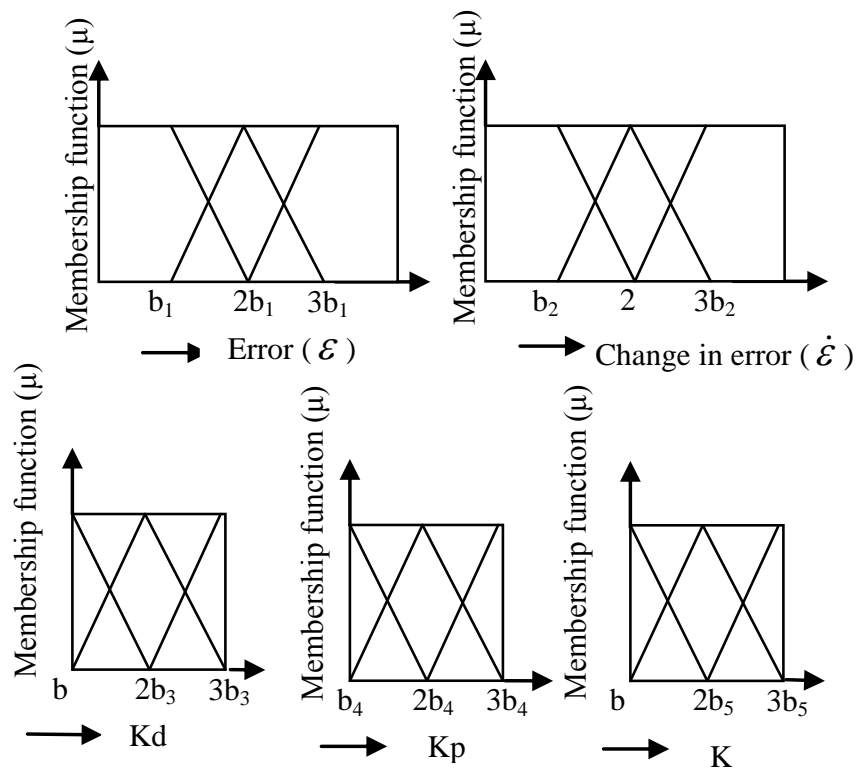

Fig. 6: Membership function distribution of FLC

Table 1: Fuzzy logic rule base

\begin{tabular}{|c|c|c|c|c|c|}
\hline Rule No. & $\varepsilon$ & $\dot{\varepsilon}$ & Kp & Kd & Ki \\
\hline 1 & NL & NL & L & L & H \\
\hline 2 & NL & Z & L & M & H \\
\hline 3 & NL & PL & L & M & M \\
\hline 4 & Z & NL & L & M & M \\
\hline 5 & Z & Z & M & M & M \\
\hline 6 & Z & PL & M & H & M \\
\hline 7 & PL & NL & H & M & L \\
\hline 8 & PL & Z & H & H & L \\
\hline 9 & PL & PL & H & H & L \\
\hline
\end{tabular}

Simulink model of the DAST with fuzzy-tuned PID controller is presented in Fig. 7.

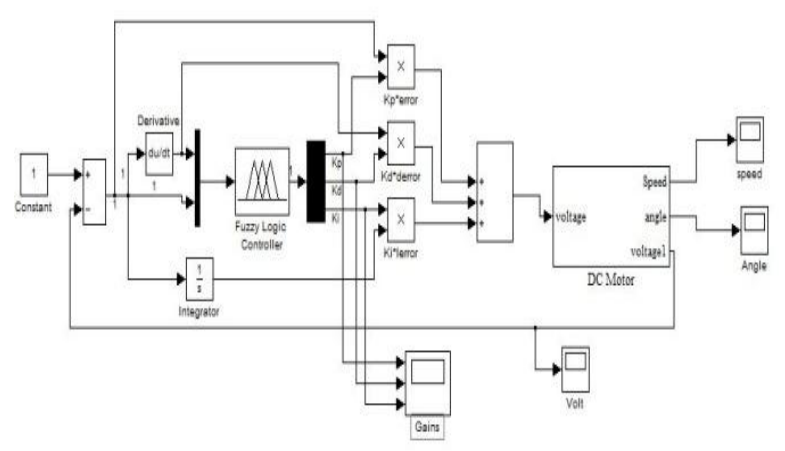

Fig. 7: SIMULINK model of fuzzy based PID controller 


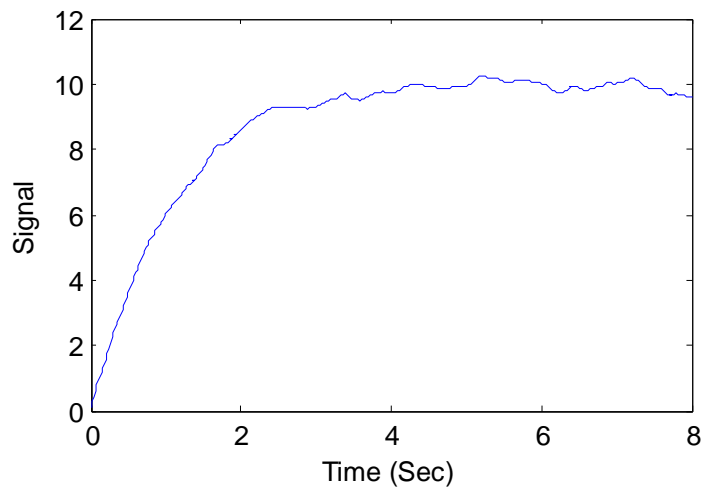

Fig. 8: Response of DAST with PID controller $(K p=10$, $\mathrm{Kd}=\mathbf{4}$ and $\mathrm{Ki}=2$ ).

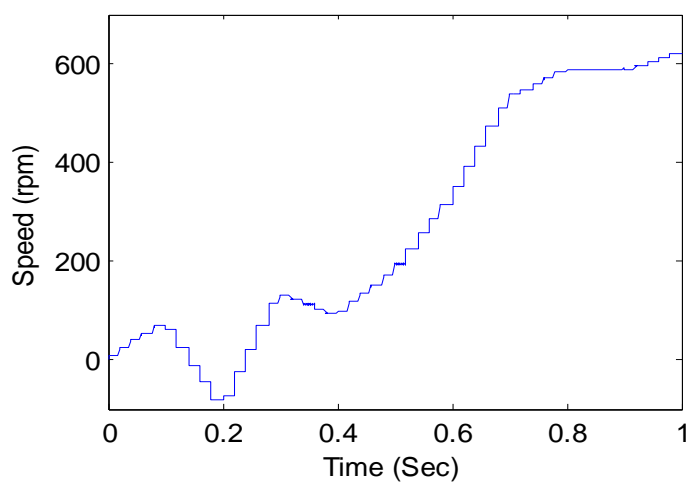

Fig. 9: Speed time curve using PID controller

Therefore, an attempt has been made to tune the gains of the PID controller using two methods. Firstly, it is tuned automatically using Ziegler-Nichols method in Matlab environment. In this process, optimal gain parameters are found to be $\mathrm{Kp}=0.0094737, \mathrm{Ki}=0.94737, \mathrm{Kd}=0, \mathrm{~N}=100$. Results corresponding to the $\mathrm{ZN}$-tuned PID controller is presented in Figures 10 and 11, respectively. A huge improvement is noticed corresponding to stability as well as speed control of the system. Settling and rise times are observed to be 2.32 and 4.14 seconds with no overshoot.

Thereafter, an FLC is applied to tuning the PID controller gains. During this error input is varied between -10 to 10 and differential change in error is varied from -250000 to 0 . Here, the gains of the PID controllers are varied in a range and they all are altercated with respect to time. The response of the DAST is shown in Figure 12 and speed-time graph is presented in Figure 13. It has been observed that both settling rise time is much lower compared to $\mathrm{ZN}$-tuned controller. It also indicates that with fuzzy-tuned PID controller, the system very quickly it reaches the rated speed. Also, signal response is much more stable compared to the $\mathrm{ZN}$-tuned controller.

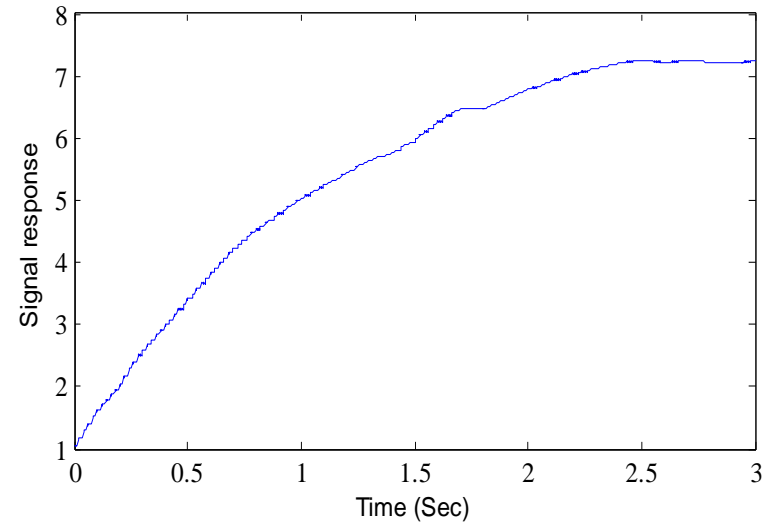

Fig. 10: Response of DAST with ZN-tuned PID controller

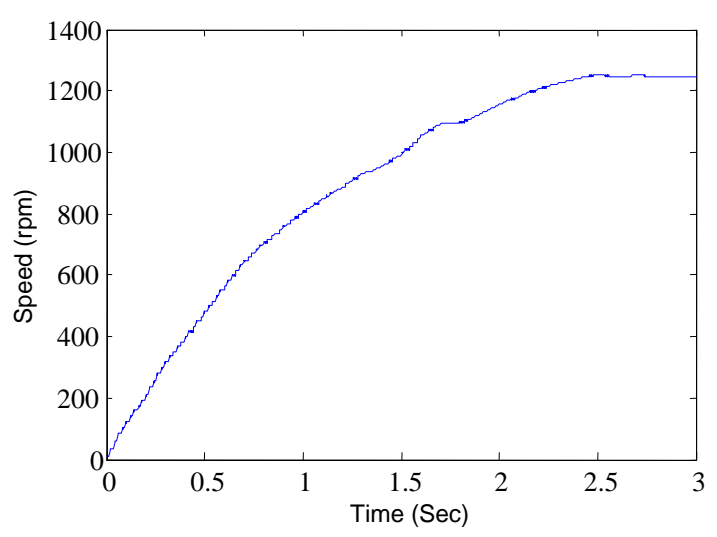

Fig. 11: Speed time curve using ZN-tuned PID controller

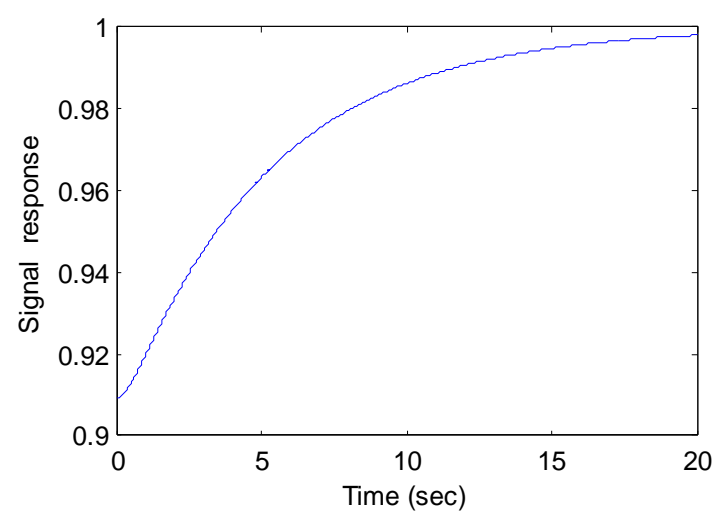

Fig. 12: Response of DAST with fuzzy-tuned PID controller. 


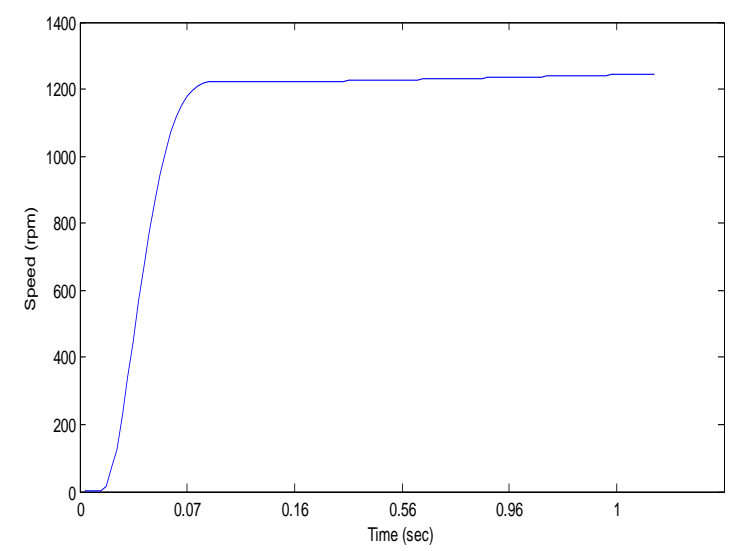

Fig. 13: Speed time curve using fuzzy-tuned PID controller

With the implementation of this fuzzy-tuned PID controller, we have tried to measure the power generation of the prototype model as shown in Figure 3. The result is presented in Table 2. Date and place of the experiment were $1^{\text {st }}$ April, 2016 at Durgapur City $\left(23.55^{\circ} \mathrm{N}, 87.32^{\circ} \mathrm{E}\right)$, India, and average irradiance is $692 \mathrm{~W} / \mathrm{m}^{2}$. It is seen that there is enormous improvement during odd hours when the Sun is not properly directed. Also, the average improvement label is quite high. Therefore, it can clearly be said that the fuzzytuned PID controller can provide better results for Solar Tracking.

Table 2: Power generation by the prototype DAST as shown in Fig. 3.

\begin{tabular}{|c|c|c|c|}
\hline Hour & $\begin{array}{c}\text { Power for } \\
\text { fixed mount } \\
\text { (in watt) }\end{array}$ & $\begin{array}{c}\text { Power for } \\
\text { DAST control } \\
\text { (in watt) }\end{array}$ & $\begin{array}{c}\text { \% of power } \\
\text { enhancement }\end{array}$ \\
\hline 08.00 & 2.00 & 6.25 & 68.0 \\
\hline 09.00 & 3.95 & 6.75 & 41.5 \\
\hline 10.00 & 4.42 & 7.72 & 42.7 \\
\hline 11.00 & 7.05 & 9.35 & 24.6 \\
\hline 12.00 & 8.82 & 11.04 & 20.1 \\
\hline 13.00 & 10.5 & 13.72 & 23.5 \\
\hline 14.00 & 12.5 & 13.08 & 4.4 \\
\hline 15.00 & 10.53 & 12.05 & 12.6 \\
\hline 16.00 & 8.61 & 10.3 & 16.4 \\
\hline 17.00 & 5.06 & 9.00 & 43.8 \\
\hline
\end{tabular}

\section{CONCLUSION}

Demand on PV system is increasing day by day because of its inherent advantages. The efficiency of solar energy is less. So, energy enhancement approaches are taken by the authors by modeling of solar power system. Firstly, dual axis sun tracking system is designed by using PID controller and LDR sensors. The gains of PID controller are tuned using two methods, namely Ziegler Nichols and using a Fuzzy logic controller. ZN-tuned PID controller provided improved results compared to the normal PID controller. Fuzzy-tuned PID controller has provided the best results in this context. Using fuzzy-tuned PID controller, average $29.76 \%$ improvement in generation of power has been observed using a prototype model. This type of DAST system maintains the sustainable angle $90^{\circ}$ between solar panel and sun rays and enhance the generation of solar power. Therefore, presently developed controller can well be applied for a PV system.

The present paper can be extended in a number of ways. Presently, the gains of the PID controller have been tuned using an FLC. It has been observed that the performance of an FLC depends on its knowledge base, which are to be optimized to get better results. Authors are presently working with this.

\section{REFERENCES}

[1] Foley. G, Photovoltaic application in rural area of developing world, Tech Rep., World Bank, Newyork, 1995.

[2] Daut. I, Irwanto. M, Irwan. M.Y, Gomesh. N, Ahmed. S. N., Three Level single phase photovoltaic and wind power hybrid inverter, Energy Procedia, 18, 1307-1316, 2012.

[3] Lopez. O, Freijedo. D. F, Yepes. G. A, Fernandezcomessa P, Malvar. J, Teodorescu.R, and Doval-Gandoy $\mathrm{J}$, Eliminating ground current in a transformer less photovoltaic application, IEEE Trans. Energy conversion, 25(1), 140-147, 2010

[4] Yakup. A.M. and Malik.Q.A, Optimum tilt angle and orientation for solar collector in Brunei Darussalam, Renewable Energy, 24, 223-234, 2001.

[5] 12. Saravanan C., Panneerselvam M.A., Christopher I.W. A novel low cost automatic solar tracking system. Int. J. Comput. Appl. 31, 62-67, 2011.

[6] Ponniran A., Hashim A., Joret A. A design of low power single axis solar tracking system regardless of motor speed. Int. J. Integr. Eng., 3, 5-9, 2011.

[7] Chong K.K., Wong C.W. General formula for one-axis sun tracking system and its application in improving tracking accuracy of solar collector, Solar Energy, 83, 298-305, 2009.

[8] Ponniran A., Hashim A., Munir H.A. A Design of Single Axis Sun Tracking System. Proceedings of the 5th International Power Engineering and Optimization Conference; Selangor, Malaysia. 6-7 June 2011; pp. 107-110.

[9] Barsoum N. Fabrication of dual-axis solar tracking controller project. Intel. Control Autom, 2, 57-68, 2011.

[10] Barsoum N., Vasant P. Simplified solar tracking prototype. Global J. Technol. Optimiz, 1, 38-45, 2010.

[11] Bajpai P., Kumar S. Design, Development and Performance test of an Automatic Two-Axis Solar Tracker System. IEEE India Conf., Hyderabad, India. 2011; pp. 1-6.

[12] Dasgupta S., Suwandi F.W., Sahoo S.K., Panda S.K. Dual Axis Sun Tracking with PV Cell as the Sensor, Utilizing Hybrid Electrical Characteristics of the Cell to Determine Insulation. IEEE Int. Conf. on Sustainable Energy Technologies; Sri Lanka. 2010; pp. 1-5.

[13] Yan Z., Jiaxing Z. Application of Fuzzy Logic Control Approach in a Microcontroller-Based Sun Tracking System. Proc. of WASE Int. Conf. on Information 
Engineering; Beidaihe, China. 14-15 August 2010; pp. 161-164.

[14] Ozuna G., Anaya C., Figueroa D., Pitalua N. Solar Tracker of Two Degrees of Freedom for Photovoltaic Solar Cell Using Fuzzy Logic. Proc. of the World Congress on Engineering; London, UK. 6- 8 July 2011; pp. 1410-1413.

[15] Li G., Shi X., Fu C., Zhou G. Design and Implementation of a Novel MPPT Controller Based on Sun Tracking Technology. Proc. of the 11th Int. Conf. on Electrical Machines and Systems; Wuhan, China. 17-20 October 2008; pp. 2611-2615.

[16] Hanieh A.A. Solar Photovoltaic Panels Tracking System. Proc. of the 6th WSEAS Int. Conf. on Dynamical Systems and Control; Sousse, Tunisia. 3-6 May 2010; pp. $30-37$.

[17] Serhan M., El-Chaar L. Two Axis Sun Tracking Systems: Comparison with a Fixed System. Int. Conf. on Renewable Energies and Power Quality; Spain. 23-25 March 2010

[18] Sharma. P, Malhotri Nitesh, solar tracking system using microcontroller, Proc. of Int. Conf. on Non-Conventional Energy (ICONCE 2014), pp.77-79 2014.

[19] Ulgen Koray, Optimum tilt angle for solar collectors. Energy sources, Taylor and Francis, 28, 1171-1180, 2006.

[20] Semma. P.R, and Imamura. S.M, Sun tracking controller for multi $\mathrm{kW}$ photovoltaic concentrator system, $3^{\text {rd }}$ Int. Photovoltaic Sol Energy Conf, Cannes, France, 1980, 2731.

[21] Ozcelik. S, Prakash. H, Challoo. R, Two axis solar tracker analysis and control for maximum power generation. Procedia Comp. Science, Elsevier, 6, 457462, 2001.

[22] Canada. J et al., Design of a sun tracker for automatic measurement of spectral irradiance and construction of an irradiance database in the 330-1100 $\mathrm{nm}$ range, Renewable energy, 32, 253-268, 2007.
[23] Matsuo. H, Shigemizu. T, Kurokawa. F. and Watanabe. $\mathrm{N}$, Characteristics of the multiple-input DC-DC converter, in proc. IEEE PESC, 1993, pp. 115-120.

[24] Koutroulis Eftichios et al., A new Technique for Tracking the Global Maximum Power Point of PV Arrays Operating Under Partial-Shading Conditions. IEEE Journal of Photovoltaic, 2(2), 184-190, 2012.

[25] Thulasiyammal. C and Sutha. S, A comparative study of maximum power point tracking (MPPT) of a solar powered UPS using DC DC boost converter, International journal of power control signal and computation, 3(1), 110-112, 2012.

[26] Shicheng Zheng, Liu Wei, Research and implementation of photovoltaic charging system with maximum power point tracking, IEEE, 2008.

[27] Lohner. A, Meyer. T, and Nagal. A, A new panelintegratable inverter concept for grid connected photovoltaic systems, IEEE Int. Symp. Indl Electronics, 1996, pp. 827-831.

[28] Taib. S, Sutanto. Y, and Razak. A.R.A, Development of simple PWM inverter using photovoltaic cells, Student conference on research and development processing, 2002.

[29] Selamogullari U.S, Torrey. D.A., Salon. S, A system approach for a stand-alone residential full cell paver inverter design, IEEE Trans. Energy conversion, 25(3), 741-749, 2010.

[30] Oldenkamp H, De Jong. I, Baltus C., Baltus. S, Verhoeven, and Elstgeest. S, Reliability and accelerated life tests of the ac module mounted OKE4 inverter, in Proc. 25th IEEE Photovoltaic System Conf., 1996, pp.1339-1342.

[31] Meinhardt. M. et al., Miniaturized low profile module integrated converter for photovoltaic applications with integrated magnetic components, in Proc. IEEE Applications Power Electron. Conf. Expo., 1999, pp. 305-311.

[32] Calais. M, Myrzik .J, Spooner. T,, Agelidis. V, Inverters for single-phase grid connected photovoltaic systemsan overview, IEEE Power Elect. Specialists Conf., 2002, 1995-2000. 